\title{
TRANSLATING PSM POLICY INTO PRODUCTION PRACTICES
}

\author{
STUDYING NEWSROOM MANAGEMENT \\ STRATEGIES TOWARDS AUDIENCE \\ ENGAGEMENT
}

\author{
Marleen te Walvaart \\ University of Antwerp \\ Research group Media, Policy and Culture \\ Sint-Jacobsstraat 2 \\ 2000 Antwerp \\ Belgium \\ Marleen.teWalvaart@uantwerpen.be
}

\begin{abstract}
PSM policy documents aim at interactive audience engagement, but production practices show many limitations to achieve this. This article studies how PSM policy is translated into practice, by analysing the newsroom management strategies concerning audience engagement. In-depth interviews were conducted with managers at different levels of the Flemish public service company VRT. Results show that managers primarily aim at immersive engagement through newsroom convergence and VRT brands. They value interactive engagement as well, but those experiments remain vulnerable. Newsroom management strategies are closely based on practices and audience behaviour, while there is a much larger distance with broader VRT policy.
\end{abstract}

Keywords: public service media, audience engagement, newsroom strategies, media management, Flanders

\section{Introduction}

This article studies public service media (PSM) newsroom management strategies concerning audience engagement. Digital media have increased the ways in which audiences can engage with media. Audiences can watch the news when they want to on different devices (immersive engagement) and social media platforms provide easy access to interact and participate (interactive engagement). PSM policy documents promise interaction and participation with the audience, while production practices show many limitations. ${ }^{1}$ This raises the question which strategies newsroom managers use to translate policy ideas into practice.

In order to study management strategies, this article studies how the VRT (PSM company of the Flemish, northern, Dutch-speaking part of Belgium) newsroom management wishes to engage the audience, which strategies they communicate to the editorial offices, and how they integrate VRT policy to achieve this. The 2016-2020 management 
contract between VRT and the Flemish government explains it aims at interaction and participation with news consumers, but it does not further explain how to do this. ${ }^{2}$

Earlier management and production studies show how digital media have complexified the strategic context for PSM. ${ }^{3}$ PSM continuously adapted their strategies to respond to changing audience behaviour, for example through converging media platforms in the newsroom. ${ }^{4}$ However, changing production practices seems to be a slow and delicate process, which has caused friction between managers and producers. ${ }^{5}$

In-depth qualitative interviews with managers at different levels of VRT have been conducted in order to analyse the current newsroom management strategies. The analysis illustrates that VRT managers primarily aim at immersive engagement, in which audiences do not interact. To reach that, new convergent newsroom structures inform the audience on different platforms and VRT brands help to differentiate content. Besides immersive engagement, some newsroom managers also stimulate interactive engagement. However, these initiatives operate at an experimental level and remain vulnerable. Newsroom managers' strategies rely largely on newsroom practices and audience preferences and they feel distanced from VRT policy. VRT policy stimulates immersive engagement for news content, but does not stimulate the incorporation of interactive audience engagement in the newsroom. In this way, newsroom managers do not have a nuanced framework for the varieties of audience engagement that they can rely on.

\section{Theory}

Digital media platforms have increased the ways that audiences can engage with media. Audiences can easily reach out to the content they wish for, at the moment they want to, on the platform they want to. At the same time, social media provide easy possibilities to interact, participate and produce content. ${ }^{6}$ Dividing these ways into immersive, interactive and para-active engagement, helps to categorise the varieties. With immersive engagement, audiences feel connected with media content without adding content. ${ }^{7}$ This invisible type of engagement is often neglected in research, while Barnes describes this as the 'silent' majority of the audience, to point out the large amount of people that remain invisible. ${ }^{8}$ Today, audiences can engage with media content across many platforms. Second, interactive engagement discusses visible ways of responding to media content, such as liking or sharing content on social media, or sending a tweet to producers. ${ }^{9}$ Also when producers invite audiences to participate in decision making processes, ${ }^{10}$ this is considered a form of interactive engagement. Social media have increased the opportunities for media companies to have a more responsive relationship with their audience, but it is not new, since audiences have always been able to interact with producers via letters or phone calls. Third, para-active engagement involves audience content production which is related to media content, but is not a direct response to original content. This includes engaging in competitions that producers have set out, or posting videos on social media in which original content is re-edited or new storylines are created. ${ }^{11}$

Different scholars mention the potential of interactive engagement specifically for PSM. They see it as the duty of PSM to approach the audience as citizens, whose perspectives they can include. ${ }^{12}$ Lowe and Bardoel suggest a transition from a supply-oriented thinking to demand-oriented thinking in the production strategies, which concerns a more audience centred view. ${ }^{13}$ However, Nissen mentions this is not evident for PSM:

[...], public service media often find it difficult to adapt to their new role, that of a facilitator of interactive discussions. But that is precisely what will be expected of them by the Facebook, Twitter and YouTube generations. ${ }^{14}$

PSM policy documents mention a variety of audience engagement. The council of Europe includes several roles for PSM as forums for democratic debate and public discussion, and providers for interactive engagement. ${ }^{15}$ 
These explicit policy aims make it interesting to study PSM. In addition, PSM are major and trusted providers for news and information in many European countries. ${ }^{16}$ In Flanders, the VRT management contract with the government (2016-2020) approaches the VRT audience as users who are autonomous and follow their own needs for information. ${ }^{17}$ It mentions VRT has to aim for interaction, dialogue, participation and co-creation with the audience, but it does not further define the concepts, or specify how these relate to news content. This allows creative freedom within the organisation, but it makes it hard to understand what VRT management aims are and even provides the impression that there might not be a clear aim. ${ }^{18}$

In comparison to policy aims, media production studies, both in public service and commercial media, show that producers often encourage immersive engagement in which the audience does not provide visible input. ${ }^{19}$ The integration of online media has increased the potential for a more interactive engagement with producers, but it seems difficult for PSM to adapt to a more interactive relation with the audience. Only a minority of media producers engage with their audience interactively. ${ }^{20}$ Specifically in a newsroom context, producers remain strongly attached to professional values, such as objectivity and immediacy, in which interactive engagement seems to conflict with standardised routines. ${ }^{21}$ Moreover, integrating participation is difficult, since producers want to keep their editorial power. ${ }^{22}$ While there are examples of successful interaction and participation to engage audiences, these interactive ways of engagement are limited. ${ }^{23}$

As such, this shows a remarkable difference between PSM policy aims towards more interactive engagement, and actual production practices that focus on immersive audience engagement. It remains unclear how management strategies at media companies play a role in deciding on the ways of audience engagement. In order to understand how PSM managers interpret and integrate policy aims in the newsroom and how they motivate producers to engage the audience, this article analyses newsroom management strategies.

Management strategies are the activities and dynamics which translate policy ideas into concrete operational plans to be able to improve production practices. In an organisation structure, these so-called middle managers can have an important position to translate policy ideas into production practices and vice versa. ${ }^{24}$ In a PSM newsroom, newsroom management consists of middle managers, as the managers are both responsible for managing different editorial offices and for reporting to the board of directors. This article focuses on this middle management function in between the board of directors and editors-in-chief in the organisational structure. ${ }^{25}$

A central management strategy that has been studied is newsroom convergence. ${ }^{26}$ In short, when newsrooms converge, editorial offices are restructured to produce multimedia content, whereas before they were structured to produce content for each medium separately. ${ }^{27}$ It aims to integrate the production of television, radio and online content more equally within a shared work culture. ${ }^{28}$ Deuze explains how the more central role for online media and social media allows to engage audiences in a more interactive and even participatory way. ${ }^{29}$ However, the implementation of convergence strategies seems to be a slow and delicate process, which can cause friction between managers and producers, because of the differences between the organisational structures in which managers operate and the professional cultures of producers. ${ }^{30}$ Issues such as the bureaucratic structures of PSM, deeply rooted routines and identities, too little internal communication and the lack of trust between managers and producers caused difficulties in many production PSM newsrooms. ${ }^{31}$ At VRT as well, a convergence project in 2007 resulted in few actual changes in the production processes. ${ }^{32}$ As such, social, cultural and contextual factors seem to be more decisive for the success of convergent strategies than the technological opportunities. ${ }^{33}$ Consequently, it remains unclear how convergence might lead to changes in the way producers engage their audience.

This theoretical framework has distinguished different types of audience engagement. It showed how production practices show limited interactive engagement with audiences, while PSM policy presents potential and aims for interactive engagement. Management strategies can explain this translation from policy to practice. Many newsrooms integrate strategies to converge the newsroom, which might change how the audience can engage. 
M. te Walvaart, Translating PSM Policy into Production Practices

\section{Method}

This paper discusses three questions to be able to analyse the newsroom managements strategies concerning audience engagement. Together, the focus on newsroom management enables to analyse the translation from VRT policy to editorial office practices. First, what are the newsroom managers' aims concerning audience engagement? Second, how do newsroom managers concretise these aims for the editorial offices into strategies? Third, how do newsroom managers integrate VRT policy?

Eight in-depth interviews were conducted with managers across different management levels at VRT between April and September 2018. The interviews took place in Dutch at the VRT and lasted between 50 minutes and 1,5 hours. These allowed for the researcher to understand the organisational structures of the different management levels, and centrally, to obtain a nuanced image of the managers' views and activities regarding audience engagement. Semi-structured topics ${ }^{34}$ covered: organisational structures, aims with regards to audience, communication of aims, the use of policy documents, and opinions about audience interaction.

Interviews were conducted with the newsroom management, consisting of five managers, i.e. the executive editors in the newsroom, and the newsroom director. Each manager is responsible for a different part of newsroom content. Manager Griet De Craen is responsible for radio, ${ }^{35}$ manager Inge Vrancken for TV news ${ }^{36}$ and manager Steven Samyn for current affairs television ${ }^{37}$. Newsroom managers for sports and digital were unable to participate in this research project. The newsroom director, Liesbet Vrieleman, ${ }^{38}$ was interviewed and she is also part of the VRT board of directors. To obtain a view of the broader VRT policy aims, interviews were also conducted with strategic director Lut Vercruysse ${ }^{39}$ and corporate development manager Wouter Quartier ${ }^{40}$ in the board of directors. The newsroom management collaborates with content managers of different VRT brands and with the VRT research department. Therefore, interviews were also conducted with Lotte Vermeir, content manager of VRT brands Eén and Canvas, ${ }^{41}$ and Tomas Coppens, researcher of newsroom content. ${ }^{42}$

Alongside the interviews, a document analysis of VRT policy documents supported the interviews. These allowed us to gain more insights in how VRT is organised and how audience engagement is formalised in policy. As these documents had a supportive aim, they were mainly used to embed the interviews within their own context. ${ }^{43}$ These documents consisted of the 2016-2020 and 2012-2016 management contracts, annual reports, programme charters, and internal documents with three-year strategies. Since some of the internal documents are confidential, the arguments in this article are always supported by interview data.

To analyse the data, different topics categorised the interviews and the policy documents. Topics were both deductively chosen, based on the interview topic list, and inductively, based on the data collection itself. This resulted in several central topics: reorganisation of the newsroom, VRT brands, and opinions about interactive engagement.

\section{Analysis}

This analysis explains several newsroom strategies that aim at immersive engagement. Then, it discusses the considerations of newsroom managers to experiment with more interactive engagement, but how these are discouraged in broader VRT policy aims.

The first strategy discussed here is newsroom convergence. The newsroom managers at VRT initiated a large-scale convergent project in 2017, in which the editorial offices are not organised and separated between television, radio and online media, but according to the different topics they cover. With this strategy, newsroom managers encourage journalists to produce content for several media platforms. The decision to initiate this convergence strategy was 
grounded in a large audience survey conducted by the VRT research department. The results made the newsroom management realise that people consume news content across a variety of online platforms, while the organisational structures were still strongly rooted in radio and television production traditions.

This convergence project is very similar to the strategies that many other PSM institutions have implemented as well. However, these initiatives have often lead to limited success, due to frictions between managers and producers. ${ }^{44}$ Equally at VRT, the newsroom initiated a similar project in 2007, which led to little actual changes because of the lack of internal communication between managers and producers. ${ }^{45}$ Newsroom director Vrieleman recognises the difficulties to reorganise the production routines, but she also experiences that an increasing amount of colleagues feel the necessity to adapt:

Our digital footprint has to increase at VRT news. Everybody knows that, because we will not survive with linear television only. So everybody is convinced, but to actually change the processes is difficult for many people and it takes time [...] (Newsroom director, Vrieleman).

The newsroom managers feel that they have to continue explaining the need for the new newsroom structure, but that journalists increasingly start to adapt their practices.

This strategy allowed to increase the importance of online platforms and decrease the central position of television in the production processes to respond to changing audience behaviour. Manager for radio De Craen argues: "We realised you can no longer expect the audience to find you, you have to find the audience." Basing management strategies on audience ratings and preferences, implicates a more reactive response to the audience. This suits the transition that Lowe and Bardoel suggested towards more demand-oriented thinking. ${ }^{46}$

This integration of online media might encourage more interactive engagement. ${ }^{47}$ However, managers still primarily focus on providing content in which the audience remains invisible. Newsroom director Vrieleman explains this focus on immersive content, as they have the role as information providers: "We have to infiltrate the environments of users, and still bring the news that we think is important." As a public broadcaster, the newsroom management aims at informing a broad range of people in Flanders to offer trustworthy news content. Newsroom director Vrieleman explains: "Trustworthiness is our greatest asset, I think we are living in a time, what can you believe and what not on Facebook? I hope that when people see VRT news, they know, I can trust this." The arguments indicate similar references to the professional values limiting interaction that earlier studies have found. ${ }^{48}$

A second central strategy to encourage immersive engagement is differentiating content based on different VRT brands. Brands are groups of content collected under a name, in which each have their own tone of voice to attract a different target audience. The newsroom centrally produces content for the different VRT brands, besides its own digital brand VRTnws, in which the topic choices and tone of voice are adapted to the target audiences. Differentiating content across brands allows these different audiences to immerse in and connect with the VRT content.

The focus on differentiated content across platforms fits within VRT policy because policy is strongly based on different brands. The management contract with the government states that VRT should engage its audience through these brands: "The brands of the VRT are the most important connectors between the media user and content" (Management contract 2016-2020, p. 24). VRT policy requires differentiated content from the newsroom that suits each brand. For example, programmes for television channel Eén (One) have to connect a broad range of people in Flanders to be able to "Feel and feed the heartbeat of Flanders" (content manager, Vermeir), whereas productions for Radio 1 can be much more narrow as it identifies as a brand which actively shapes societal debates and stimulates new insights. Strategic director Vercruysse clarifies: "The newsroom has to be able to identify with the USP (unique selling point) of the brand".

The content managers who are responsible for the VRT brands have a very central position in the organisational structure of VRT. They can decide how they wish to engage the audience with brand content, and can order news content produced by the newsroom with a certain format and tone of voice. This has caused friction between 
managers inside the newsroom and content managers outside the newsroom in the past, but in the recent years the collaboration has improved. More than before, newsroom managers are in dialogue with the content managers to agree on the format and tone of programmes. Newsroom director Vrieleman points out: "We have evolved immensely in the past year, we work together with the brands more closely than before".

While the management contract proscribes that all VRT brands have to conduct a participatory project, the brand managers, who are responsible for dividing these projects, decided to assign the participatory projects to non-news programmes. Some interactivity on social media is regarded as positive for the brands, but this is explicitly discouraged in the newsroom. Newsroom director Vrieleman explains that only when proposals with audience interactivity are fully embedded within a brand identity, it has been possible for the newsroom to do some projects. The newsroom research department, which plays an advisory role but whose research output has a large impact on newsroom strategies, also discourages direct audience interaction. The researchers advise the newsroom to rely on audience research to stay aware of who the audience is and to take into account audience preferences to connect with the audience, but not to interact with them directly.

Apart from the brands which centrally guide VRT policy, most newsroom managers feel a large distance from VRT policy when they devise newsroom management strategies in relation to audience engagement.

Of course, we are a public broadcaster so there has to be some kind of control. But this remains a theoretical aspect of my job for me, in which we often have to write down aspects that are evident to us (TV news manager, Vrancken).

Whereas earlier studies ${ }^{49}$ explained that there can be a distance between managers and producers, primarily when management strategies change, VRT newsroom strategies show a larger distance between managers inside the newsroom and the broader VRT policy. Newsroom managers feel a necessity to work with the management contract since they are a public broadcaster, but they feel much more closely related to and rely much more on newsroom practices and audience behaviour. The managers explain: "Shifting our focus to the audience has evolved a lot in the recent years" (radio manager, De Craen). Newsroom managers integrate audience research conducted by the VRT study department. The VRT study department conducts a large amount of audience research to gain insights in audience behaviour and preferences. "I value our study department a lot, our gut feeling is important, but sometimes the numbers are very important as well" (current affairs manager, Samyn).

The distance with VRT policy can be explained by two central reasons. First, the VRT management contract provides few details. ${ }^{50}$ The board of directors chooses to remain very broad on purpose: "We try to tell a story that inspires and at the same time we have to respect the autonomy of the producers because it is a creative sector" (corporate development manager, Quartier). Second, the newsroom is editorially independent and has its own journalistic code of ethics. It is situated in a separate building and has a separate staff. In that sense, the newsroom almost feels as if it is a separate company beside VRT that is centrally producing content for different VRT brands and producing some content for its own digital brand.

Both the VRT managers inside and outside the newsroom prioritise immersive audience engagement with news content, but some newsroom managers argue that interactive audience engagement cannot be ignored either. The newsroom increasingly receives large amounts of comments which often question why certain production choices are made. Manager radio, De Craen explains: "I notice that the audience is getting more assertive and has questions. The relationship with the audience in 2018 forces us to more openness." To respond to this input, newsroom managers motivate journalists to be more transparent in online, radio and TV content, on why they made certain choices, to provide trustworthy news:

I think transparency is very important to gain audience trust. We try to focus on that more and more. Sometimes we have to admit our mistakes, it demands a lot of time, but I think we live in an era where we have to do this (TV news manager, Vrancken). 
M. te Walvaart, Translating PSM Policy into Production Practices

In addition, the newsroom management recently hired an ombudsman in order to respond to the increasing amount of audience reactions. Both illustrate again how the newsroom management strategies react very centrally to audience behaviour to engage the audience.

Moreover, some newsroom managers want to encourage more direct audience interaction as well. Newsroom director Vrieleman demonstrates the necessity: "I fear that today our focus is one-way-traffic [...] I think we have to search for systems in which we can ask for the know-how of people much more." The newsroom managers argue that while their main aim is producing news, interaction with the audience has the journalistic potential to find out what topics people care about and take into account those issues as well.

I think producing radio with your audience gives it some relevance because people care about these topics [...] Of course our first job is to inform people about what happens [...] I feel we do a better job if we are in contact with our audience every now and then and ask what they find important (radio manager, De Craen).

The newsroom management is currently encouraging several experiments with interaction in different projects. "We have made a long journey because the newsroom did not communicate with its audience for decades" (radio manager, De Craen). At the same time, the managers also remain unsure how to include it. The television news manager points out that interaction is a complex process:

We live in a time were part of the audience feels journalists work in a bubble and we dictate to much. [...] To be trusted, we have to see what our audience thinks, what keeps them busy, and then decide as gatekeepers what to do with it. [...] We are still searching for the best ways to interact more with the audience. We feel that it is necessary, and it seems easy, [...] but it is something we are still figuring out (TV news manager, Vrancken).

The newsroom managers experience that interaction on social media platforms offers opportunities, but is very vulnerable and challenging as well. It has the risk to create a distorted image of opinions in society:

Now we try to organise Facebook live events around big topics including an expert and we encourage people to ask questions. [...] But there are so many traps in social media, I feel that everyone is still struggling with how best to deal with them (TV news manager, Vrancken).

Interactive engagement strategies are still mostly experiments and receive little support from VRT management levels outside the newsroom: "We get the explicit task to be independent and to not include opinions" (radio manager, De Craen). By discouraging interactive engagement in VRT's policy, a nuanced vision about audience engagement for the newsroom at policy level is missing. In this way, there is no broader framework that can help newsroom managers and producers with the complexities that they experience to build projects with various kinds of audience engagement.

\section{Conclusion}

This article studied PSM newsroom management strategies concerning audience engagement. Digital media have increased the opportunities for audiences to engage with media, which lead to interactive aims in PSM policy, while production practices show many limitations and focus on immersive engagement. This article has shown that management strategies can help explain this inconsistency in the translation from PSM policy to production practices.

VRT newsroom management strategies primarily focus on immersive engagement to adapt to digital media. Mainly, newsroom strategies aim at offering content across different platforms with a convergent newsroom structure and differentiating news content based on different VRT brands. The broader VRT policy stimulates immersive 
engagement for news content, while one might expect VRT policy to support interactive engagement, because it aims for interaction in the management contract. However, VRT policy strongly relies on VRT brands, in which managers decided to aim for audience interaction with non-news programmes, and limit interaction with the newsroom and news content.

Some newsroom managers argue that today's media context is more complex than VRT policy suggests, and experience that part of the audience requires a more interactive engagement with news content as well. They are encouraging several experiments to engage the audience with interaction, but these attempts seem very vulnerable in a journalistic context.

While the newsroom strategies are framed in broader PSM values, newsroom managers feel distanced from VRT policy. Instead, the newsroom strategies strongly rely on newsroom practices, audience behaviour and brands to engage the audience in a digital context. Whereas existing production studies found a distance between management strategies and practices, ${ }^{51}$ this analysis showed that there is a significantly larger distance between newsroom management strategies and broader VRT policy. VRT policy does not offer a framework or inspire newsroom managers concerning audience engagement. The VRT brands that receive a central role in VRT policy, limit opportunities for the newsroom. There is no nuanced point of view written down in the policy documents about changing ways of audience engagement in the newsroom, while this is a complex issue in a digital media context. ${ }^{52}$ It poses an interesting question for further research whether more nuanced conceptualisations about audience engagement in PSM policy can play a more supportive role or offer inspiration for management strategies to engage audiences.

\section{Notes}

1. Christian S. Nissen, 'Digitization and Public Service Media: What Service for Which Public?,' in Karen Arriaza Ibarra, Eva Nowak, and Raymond Kuhn, eds, Public Service Media in Europe: A Comparative Approach, Routledge, 2015, pp. 89-108.

2. Tim Raats, Hilde Van den Bulck, and Leen d'Haenens, eds, Een VRT Voor Morgen of Morgen Geen VRT Meer? De Publieke Omroep Tussen Politiek, Publiek, Partners en Concurrenten [A VRT For Tomorrow, Or No Longer A VRT Tomorrow? Public Broadcasting Between Politics and Audiences, Partners and Competitors], Pelckmans Pro, 2016.

3. Lucy Küng, Strategic Management in the Media: From Theory to Practice, 2nd edition, SAGE Publications, 2017.

4. Michał Głowacki and Lizzie Jackson, eds, Public Media Management for the Twenty-First Century: Creativity, Innovation, and Interaction, Routledge, 2014.

5. Steve Paulussen, 'Innovation in the Newsroom,' in Tamara Witschge, Chris. W. Anderson, David Domingo, and Alfred Hermida, eds, SAGE Handbook of Digital Journalism, SAGE Publications, 2016, pp. 192-206.

6. Nissen, 'Digitization and Public Service Media,' 2015.

7. Elisabeth Evans, 'Negotiating "Engagement” within Transmedia Culture,' paper presented at the Summer School in Cultural Studies, Jyväskylä, 13-15 June 2016.

8. Renee Barnes, 'The Ecology of Participation,' in Tamara Witschge, Chris. W. Anderson, David Domingo, and Alfred Hermida, eds, SAGE Handbook of Digital Journalism, SAGE Publications, 2016, pp. 179-191.

9. Evans, 'Negotiating “Engagement” within Transmedia Culture,' 2016.

10. Nico Carpentier, 'Interrogating Audiences: Theoretical Horizons of Participation,' Communication Management Quaterly, 21, 6, 2011, 7-12.

11. Evans, 'Negotiating "Engagement” within Transmedia Culture,' 2016.

12. Andra Leurdijk and Matthijs Leendertse, 'Follow the Audience? An Analysis of PSM New Media Strategies in Light of Conceptions and Assumptions about Audiences,' in Gregory Ferrell Lowe, ed, The Public in Public Service Media, Nordicom, 2009, pp. 151-175; Michał Głowacki and Alicja Jaskiernia, 'Conclusions: Towards Public Service Media Renewal,' in Michał Głowacki and Alicja Jaskiernia, eds, Public Service Media Renewal: Adaptation to Digital Network Challenges, Peter Lang, 2017, pp. 213-220; James Spigelman, 'Defining Public Value in the Age of Information Abundance,' in Gregory Ferrell Lowe and Fiona Martin, eds, The Value of Public Service Media, Nordicom, 2014, pp. 43-56; Lizzie Jackson, 'Participating Publics: Implications for Production Practices at the BBC,' in Michał Głowacki and Lizzie Jackson, eds, Public Media Management for the Twenty-First Century: Creativity, Innovation, and Interaction, Routledge, 2014, pp. 268-284.

13. Gregory Ferrell Lowe and Jo Bardoel, eds, From Public Service Broadcasting to Public Service Media, Nordicom, 2007.

14. Nissen, 'Digitization and Public Service Media,' 2015, p. 97. 
15. Michał Głowacki, 'New Public + New Media = New Leadership? The Council of Europe's Approach to Governance in Public Service Media,' in Michał Głowacki and Lizzie Jackson, eds, Public Media Management for the Twenty-First Century: Creativity, Innovation, and Interaction, Routledge, 2014, pp. 181-197.

16. Corine Schweizer and Manuel Puppis, 'Public Service Media in the "Network" Era: A Comparison of Remits, Funding, and Debate in 17 Countries,' in Gregory Ferrell Lowe, Hilde Van den Bulck, and Karen Donders, eds, Public Service Media in the Networked Society, Nordicom, 2018, pp. 109-124.

17. Joke Bauwens, 'De Openbare Televisie En Haar Kijkers: Oude Liefde Roest Niet? [Public Television And Its Viewers: Old Love Is Not Forgotten?]' in Alexander Dhoest and Hilde Van den Bulck, eds, Publieke Televisie in Vlaanderen: Een Geschiedenis, Academia Press, 2007, pp. 91-126.

18. Anne-Sofie Vanhaeght and Karen Donders, 'Moving beyond the Borders of Top-Down Broadcasting: An Analysis of Younger Users' Participation in Public Service Media,' Television \& New Media, 17, 4, 2016, 291-307; Raats et al., Een VRT Voor Morgen of Morgen Geen VRT Meer?, 2016.

19. Tamar Ashuri and Atara Frenkel, 'Online/Offscreen: On Changing Technology and Practices in Television Journalism,' Convergence: The International Journal of Research into New Media Technologies, 23, 2, 2017, 148-65; Marleen te Walvaart, Alexander Dhoest, and Hilde Van den Bulck, 'Production Perspectives on Audience Participation in Television: On, beyond and behind the Screen,' Convergence: The International Journal of Research into New Media Technologies, online first January 2018, 25, 5-6, 2019, 1140-1154

20. Jackson, 'Participating Publics,' 2014.

21. Nissen, 'Digitization and Public Service Media,' 2015; David Domingo, 'Interactivity in the Daily Routines of Online Newsrooms: Dealing with an Uncomfortable Myth,' Journal of Computer-Mediated Communication, 13, 3, April 2008, 680-704; Marleen te Walvaart, Hilde Van den Bulck, and Alexander Dhoest, 'Engaging the Audience in a Digitised Television Production Process: A "Hierarchy of Influences" Approach,' Journalism Practice, 12, 7, 2018, 901-917.

22. Tiziano Bonini, 'The Participatory Turn in Public Service Media,' in Michael Glowacki and Alicja Jaskiernia, eds, Public Service Media Renewal: Adaptation to Digital Network Challenges, Peter Lang, 2017, pp. 101-116; Karin van Es, 'Social TV and the Participation Dilemma in NBCs The Voice,' Television \& New Media, 17, 2, February 2016, 108-123; Donatella Selva, 'Social Television: Audience and Political Engagement,' Television \& New Media, 17, 2, February 2016, 159-173.

23. David Domingo, Thorsten Quandt, Ari Heinonen, Steve Paulussen, Jane B. Singer, and Marina Vujnovic, 'Participatory Journalism Practices in the Media and beyond: An International Comparative Study of Initiatives in Online Newspapers, Journalism Practice, 2, 3, October 2008, 326-342; Skylla Janssen, 'Publieksparticipatie Beteugeld: Boundary Work En Publieksparticipatie in de Professionele Praktijken van Nederlandse Televisiemakers [Audience Participation Tamed: Boundary Work And Audience Participation In The Professional Practices of Dutch Television Producers],' PhD dissertation, University of Amsterdam, 2017; Marleen te Walvaart, Alexander Dhoest, and Hilde Van den Bulck, 'Production Perspectives on Audience Engagement: Community Building for Current Affairs Television,' Media Industries, 6, 1, June 2019, 43-66.

24. Küng, Strategic Management in the Media, 2017.

25. Sven-Ove Horst and Johanna Moisander, 'Paradoxes of Strategic Renewal in Traditional Print-Oriented Media Firms, International Journal on Media Management, 17, 3, July 2015, 157-174.

26. Ainara Larrondo, 'News Production in the "Post-Broadcasting” Era: BBC Scotland's Move towards Convergence,' Media, Culture \& Society, 36, 7, October 2014, 935-951.

27. Mark Deuze, 'Convergence Culture and Media Work,' in Jennifer Holt and Alisa Perren, eds, Media Industries: History, Theory, and Method, Wiley-Blackwell, 2009, pp. 144-156.

28. Ainara Larrondo, David Domingo, Ivar John Erdal, Pere Masip, and Hilde Van den Bulck, 'Opportunities and Limitations of Newsroom Convergence: A Comparative Study on European Public Service Broadcasting Organisations,' Journalism Studies, 17, 3, April 2016, 277-300.

29. Deuze, 'Convergence Culture and Media Work,' 2009

30. Paulussen, 'Innovation in the Newsroom,' 2016.

31. Larrondo et al., 'Opportunities and Limitations of Newsroom Convergence,' 2016.

32. Hilde Van den Bulck and Sil Tambuyzer, 'Collisions of Convergence: Flemish News Workers' and Management's Perceptions of the Impact of PSB Newsroom Integration on Journalistic Practices and Identities,' International Communication Gazette, 75, 1, February 2013, 54-75.

33. Larrondo et al., 'Opportunities and Limitations of Newsroom Convergence,' 2016.

34. Alan Bryman, Social Research Methods, 5th edition, Oxford University Press, 2016.

35. Interview conducted with Griet De Craen, 4 July 2018, Brussels.

36. Interview conducted with Inge Vrancken, 25 May 2018, Brussels.

37. Interview conducted with Steven Samyn, 27 April 2018, Brussels.

38. Interview conducted with Liesbet Vrieleman, 3 September 2018, Brussels.

39. Interview conducted with Lut Vercruysse, 11 April 2018, Brussels

40. Interview conducted with Wouter Quartier, 16 April 2018, Brussels.

41. Interview conducted with Lotte Vermeir, 8 June 2018, Brussels. 
42. Interview conducted with Tomas Coppens, 3 May 2018, Brussels.

43. John T. Caldwell, 'Cultures of Production: Studying Industry's Deep Texts, Reflexive Rituals, and Managed Self-Disclosures,' in Jennifer Holt and Alisa Perren, eds, Media Industries: History, Theory, and Method, Wiley-Blackwell, 2009, pp. 199-212.

44. Larrondo et al., 'Opportunities and Limitations of Newsroom Convergence,' 2016.

45. Van den Bulck and Tambuyzer, 'Collisions of Convergence,' 2013.

46. Lowe and Bardoel, From Public Service Broadcasting to Public Service Media, 2007.

47. Deuze, 'Convergence Culture and Media Work,' 2009.

48. Domingo, 'Interactivity in the Daily Routines of Online Newsrooms,' 2008; Nissen, 'Digitization and Public Service Media,' 2015.

49. Larrondo et al., 'Opportunities and Limitations of Newsroom Convergence,' 2016; Paulussen, 'Innovation in the Newsroom,' 2016.

50. Raats et al., Een VRT Voor Morgen of Morgen Geen VRT Meer?, 2016.

51. Paulussen, 'Innovation in the Newsroom,' 2016; Larrondo et al., 'Opportunities and Limitations of Newsroom Convergence,' 2016.

52. Nissen, 'Digitization and Public Service Media,' 2015.

\section{Biograph y}

Marleen te Walvaart is a PhD student and teaching assistant at the University of Antwerp in the department of communication studies. Working in the Media, Policy and Culture research group, her doctoral research is focused on television production processes and the engagement of audiences in a digitizing media context from the perspectives of producers. 